\title{
TEORIAS FEMINISTAS DA POLÍTICA, EMPIRIA E NORMATIVIDADE
}

\section{Flávia Biroli}

é professora do Instituto de Ciência Política da UnB, coordenadora do Grupo de Pesquisa sobre

Democracia e Desigualdades (Demodê) e pesquisadora do CNPq. Brasília, DF, Brasil.

E-mail: <flaviabiroli@gmail.com>

http://dx.doi.org/10.1590/0102-173210/102

O campo da teoria política é diversificado, assim como é o debate na principal área disciplinar em que se situa, a da Ciência Política ${ }^{1}$. A filiação a diferentes tradições de pensamento implica a incorporação de determinados aparatos conceituais e metodológicos, assim como a adesão a referenciais normativos que incidem sobre o desenho das pesquisas e sobre os problemas de que tratam - sejam elas assumidamente normativas ou não. Com isso, as perguntas colocadas no curso de uma pesquisa e as estratégias para respondê-las podem variar muito. Variam também as informações sobre o

1 Este artigo foi desenvolvido no âmbito da pesquisa "Divisão sexual do trabalho e os limites da democracia" (CNPq/PQ). Uma primeira versão, reduzida, foi apresentada na Mesa-Redonda "Caminhos da teoria política", no $10^{\circ}$ Encontro da Associação Brasileira de Ciência Política (ABCP), em Belo Horizonte, MG, em 31 de agosto de 2016. Agradeço a Raquel Kritsch e Bernardo Ferreira por terem proposto esse debate; o artigo foi construído a partir do desafio por eles colocado e o caminho da reflexão aqui apresentada deve-se muito às indagações que colocaram como ponto de partida. Meus agradecimentos também a Luis Felipe Miguel e aos pareceristas anônimos da Lua Nova, por leituras críticas que contribuíram para a versão apresentada. Os problemas e lacunas que permanecem são, é claro, de minha inteira responsabilidade. 
mundo trazidas às discussões, que conformam os problemas enfrentados.

A diversidade das expressões de pensamento em um campo disciplinar é, no entanto, limitada. Entendidas como comunidades epistêmicas, as disciplinas implicam o compartilhamento de um conjunto de recursos expressivos, isto é, de possibilidades para que se diga algo - razoável e verdadeiro - sobre o mundo que nos cerca. A "arquitetura conceitual" de um dado campo de conhecimento está diretamente relacionada a sua coerência (Foucault, 1997 [1969], p. 77). Os objetos de conhecimento, por sua vez, não são um a priori para o qual a ciência se volta, mas um efeito de dinâmicas reguladas de produção de conhecimento. Vale notar, ainda, que as fronteiras que assim se traçam não dividem apenas as pretensões de validade reconhecidas e as que não o são, isto é, as que são silenciadas ou deslegitimadas. $\mathrm{O}$ conhecimento é hierarquizado também internamente às 174 disciplinas, que reconhecem e valorizam desigualmente as pretensões de conhecimento que abrigam.

Neste texto, discuto como as teorias feministas da política se situam no subcampo da teoria política, tendo como referência os desenvolvimentos da Ciência Política na segunda metade do século XX. Dois elementos sociopolíticos fazem do pensamento feminista sobre a política algo bastante peculiar. Trata-se, amplamente, de um pensamento elaborado por mulheres e, portanto, por aquelas que foram historicamente excluídas e são, ainda hoje, incluídas desigualmente da política institucional, que é o objeto primordial da Ciência Política. A produção e a circulação do conhecimento no mundo acadêmico também têm sido marcadas pela exclusão e pela inclusão desigual das mulheres. Não fossem esses elementos suficientes para torná-lo peculiar - e dificultar sua organização e institucionalização -, trata-se ainda de um pensamento que se define em conexão com o ativismo feminista e é abertamente referenciado por 
um valor, a igualdade de gênero. Sua própria conformação, tanto quanto as abordagens epistemológicas que nele se apresentam, coloca em xeque a ideia de que o conhecimento pode ser descolado dos valores e relações em um dado contexto, o que implica um enfrentamento com a valorização da ciência "neutra" e "isenta".

O objeto das teorias feministas não é exatamente as mulheres, mas sim instituições, estruturas e relações de poder cotidianas nas quais aquelas são posicionadas desvantajosamente. Se não falam estritamente de mulheres, são teorias que se definem a partir de suas posições e em diálogo com as lutas de movimentos sociais organizados, o que tem implicações epistemológicas e políticas. Seu problema de fundo são os sentidos e limites da política, repensada de uma perspectiva que leva em conta a posição das mulheres, isto é, de uma perspectiva de gênero. Para compreendermos o modo como se estabelecem as teorias feministas da política, tem especial importância a noção de que "a política não é algo simples a que nós nos referimos", mas "um artefato ricamente texturizado de linguagens reflexivas", o que confere ambiguidade e complexidade à relação entre teoria e prática política (Vincent, 2004, p. 9).

Situado nessa relação ambígua e complexa entre teoria e prática política, o debate feminista tem se confrontado com a permeabilidade desigual das democracias à participação de indivíduos e grupos; as configurações excludentes da esfera pública e suas hierarquias; as conexões entre as relações de poder na esfera doméstica e na esfera pública; a institucionalização e efetivação desigual do acesso a direitos de cidadania nas democracias contemporâneas; os critérios para a definição de princípios de justiça; os limites e o escopo do Estado como garantidor e como violador de direitos; as condições para a vocalização dos interesses de grupos subalternizados. Não se trata de apresentar uma lista ampla ou prioritária de temáticas, mas sim de deixar desde 
já estabelecido um ponto: o foco das teorias feministas não é específico (as mulheres, o feminino, a agenda feminista); tratam de política, de democracia, de justiça.

Esta é uma contribuição individual para uma empreitada coletiva de reflexão, inspirada na pergunta que abre o livro The nature of political theory, de Andrew Vincent (2004, p. 1): "o que pensamos que estamos fazendo quando praticamos teoria política?”. Por isso, faço primeiramente uma breve apresentação da tipologia que o autor propõe para as vertentes da teoria política, dela avançando para uma nota inicial sobre o empírico e o normativo na produção de conhecimento. Na mesma seção, observo como as teorias políticas feministas são incluídas no mapeamento de Vincent e, por outro lado, como são situadas em uma obra que analisa especificamente o desenvolvimento e a (sub) inclusão das análises de gênero na área de Teoria Política (Squires, 2008 [1999]) ${ }^{2}$.

176 Em seguida, discuto o modo como as teorias feministas da política se situam relativamente às fronteiras entre o normativo e o empírico. Por meio de análises bem fundamentadas do pensamento político e dos modelos científicos adotados em diferentes campos disciplinares, as teorias feministas têm demonstrado amplamente que o empírico não corresponde a algo autoevidente, mas resulta de processos seletivos de valorização, que conferem saliência a determinados aspectos da realidade e a apreendem a partir de perspectivas enraizadas em contextos determinados das relações e da produção do conhecimento. A seção apresenta

\footnotetext{
2 Neste texto, situo a passagem do foco nas mulheres para o foco nas relações de gênero, mas não me dedico a uma discussão conceitual sobre gênero. Em poucas palavras, o conceito de gênero abarca o processo sociopolítico de produção de identidades e posições referenciadas pelo sexo biológico. Permite descrever e analisar como as relações se definem em um dado sistema sexo-gênero, que implica caracterizações do feminino e do masculino e a atribuição de papeis diferenciados para mulheres e homens. Para textos fundadores nesse debate, ver Scott (1986) e Butler (1999 [1990]). Para uma crítica feminista do uso da categoria gênero, ver Moi (1999).
} 
críticas feministas às teorias que não tematizam as relações de gênero como problema político e epistemológico. Ressalto, a partir delas, o entendimento de que a teoria política é teoria de gênero, ainda que nenhuma palavra seja dita sobre o assunto.

Na última seção, analiso a redefinição das fronteiras da política pelas teorias feministas. Argumento que isso ocorre porque o feminismo questiona a hierarquia de valores que torna invisíveis as relações na vida doméstica cotidiana, ao mesmo tempo que demonstra que não é possível explicar as relações de poder na esfera definida como pública sem que se compreenda as conexões com a esfera definida como privada. Com isso, destacam-se outras dimensões do empírico, isto é, outras dimensões da vida às quais se atribui relevância política. Nesse ponto, analiso brevemente duas frentes de elaboração: a crítica à dualidade entre as esferas pública e privada no liberalismo e o recurso às experiências das mulheres na crítica à dominação masculina. Uma breve conclusão retoma a conexão entre os sujeitos de conhecimento - quem faz teoria - e a definição dos problemas e objetos da teorização.

O texto consiste em uma resposta, situada e específica, como não poderia deixar de ser, à questão sobre como estamos fazendo teoria política hoje. Falo a partir da minha posição como pesquisadora e teórica que tem dialogado sistematicamente com as teorias feministas da política. Meus percursos no debate feminista explicam, sem dúvida, algumas das escolhas feitas em um texto que não pretende, de modo algum, refletir todo o debate e que certamente apresenta lacunas. Além disso, embora escreva em um espaço disciplinar, institucional e geográfico bem definido, o da Ciência Política brasileira, me situo em um campo no qual, dada a economia política do conhecimento, a literatura produzida no Norte global tem sido predominante, ainda que as lutas que têm se estabelecido com a resistência das 
mulheres do Sul venham gerando novos aparatos teórico-conceituais e tornando visíveis outras experiências e problemas ${ }^{3}$. Embora essa não seja uma característica do debate feminista especificamente, considero importante registrá-la para que não seja tomada como um dado da natureza, mas sim como um efeito de como recursos financeiros e simbólicos estão distribuídos e incidem sobre o que fazemos quando fazemos teoria política.

\section{0 que pensamos que estamos fazendo quando praticamos teoria política?}

As abordagens fundacionais da teoria política são divididas por Andrew Vincent (2004) em cinco eixos, que descrevo brevemente. O primeiro deles é o das teorias definidas como "normativas clássicas", que assumiriam a existência de preocupações perenes e universais na análise da pólis. É onde estariam reunidos pensadores canônicos, remetendo a tradições que viriam do pensamento grego até os nossos dias. A ideia de que valores comuns constituem ou podem constituir a política é o ponto que retenho nesse caso, dados os propósitos desse texto. Há uma conexão entre o normativo, o comum e o universal, embora o significado desses últimos termos varie entre as abordagens normativas clássicas. O segundo eixo é o das teorias "institucionais", aquelas voltadas mais diretamente para a análise do Estado, expondo não apenas seu funcionamento e constituição, mas os valores normativos que implicam. As teorias políticas "históricas", por sua vez, constituem o terceiro eixo.

\footnotetext{
3 A divisão entre Norte e Sul global refere-se a "uma abstração histórico-política e a uma realidade complexa, heterogênea e em constante transformação" (Falquet, 2011, p. 24). O debate feminista pós e decolonial, em que vem sendo adotada e complexificada, tem se estabelecido como crítica e alternativa à produção acadêmica e literária do Norte global, inclusive àquela produzida no próprio campo feminista. Embora não tenha sido esse o caminho assumido na elaboração deste texto, deixo registrada sua importância no contexto atual das lutas e da produção de conhecimento feminista (cf. Curiel, 2007; Mohanti, 2003; Segato, 2016).
} 
Destaco nesse eixo a forte conexão entre teoria política e história do pensamento político, incontornável para se compreender o modo de transmissão dos textos clássicos na Ciência Política. Um quarto eixo (o quinto na sequência de Vincent) reúne as teorias "ideológicas". Embora sejam compreendidas diversamente em suas conexões com a teoria política, o que me parece importante para a discussão feita aqui é que nesse eixo é abordada a relação entre o conhecimento e a sociedade em que é produzido. Embora esteja presente, como problema, também na chamada teoria "histórica", é na "ideológica" que os elos entre conhecimento, poder e dominação são tematizados mais diretamente. Nela estariam situadas tanto as abordagens marxistas da relação entre determinações materiais e ideias quanto aquelas características do pós-estruturalismo, em que é ressaltado o caráter discursivo não representacional das ideias e do conhecimento.

O último eixo (aqui, mas o quarto na sequência do autor) é aquele que me concerne mais diretamente e que me permite um caminho para as reflexões que apresento em seguida, a partir das teorias feministas. Trata-se do eixo das teorias "empíricas". Na tipologia de Vincent (2004), elas correspondem ao conhecimento situado no terreno do positivismo, do behaviorismo e, a partir dos anos 1980, das teorias da escolha racional. Remetem, assim, a reivindicações de que a ciência se define em oposição à ideologia. Em um contexto específico das disputas (que eu situaria como o contexto das disputas políticas em torno dos sentidos e limites da democracia) em meados do século XX, essa oposição entre ciência e ideologia se desdobrou em uma diferenciação entre Ciência Política e Teoria Política. O empírico seria científico, enquanto o teórico seria normativo e ideológico e, portanto, não caberia nas fronteiras de uma ciência positiva. Já em meados do século XX, essa oposição foi sendo deslocada por teóricos importantes para a Ciência 
Política contemporânea, que não se esquivaram de visões históricas e normativas na elaboração de problemas e hipóteses que procuraram testar empiricamente (Vincent, 2004, p. 56), como Robert Dahl ${ }^{4}$.

Ainda que se considere que a distinção entre o empírico e o normativo nunca ultrapassou uma pretensão, mobilizando critérios de validade para o discurso científico situados em um dado estado da história da ciência e dos embates políticos, é ela que permite reunir diferentes correntes sob o rótulo de teoria política "empírica". Nesse eixo, a distinção entre fatos e valores, com a adesão aos primeiros, e o recurso a modelos e racionalizações provenientes ou inspirados nas ciências naturais - na matemática e, crescentemente a partir de meados do século XX, na economia - teriam mais importância do que em qualquer dos anteriores.

É a partir desses eixos fundacionais que deslocamentos e contestações são mapeados por Vincent (2014), ponto de partida para a empreitada coletiva de que faz parte este artigo. Mas o debate feminista entra nesse mapa de maneira bastante restrita. Sua primeira aparição, no capítulo "Bleached Foundations", situa parte desse pensamento no debate sobre justiça, em uma seção intitulada "Sexual Justice”. Figuram aí duas das principais autoras da teoria política contemporânea de língua inglesa, Carole Pateman, que em The sexual contract, de 1988, expôs as implicações da dualidade entre o público e o privado nas teorias do contrato, e Susan Moller Okin, que recebe especial atenção e figura como representante de uma crítica feminista que incorporaria a problemática de gênero mantendo a adesão a referenciais normativos liberais. São mencionados seus livros Justice, gender, and the family, de 1989, e Women in Western political thought, de 1979. É no primeiro que a autora

${ }^{4}$ Jawdat (2014) apresenta uma síntese dos diferentes momentos na obra de Robert Dahl em que se pode perceber esse movimento. 
assumiu mais claramente um entendimento de que é possível adaptar concepções liberais de justiça - leia-se, a abordagem de John Rawls em A theory of justice (1971) -, de modo que não excluiriam as relações de poder na esfera doméstica (a esse respeito, cf. Biroli, 2010) ${ }^{5}$.

Embora Vincent (2004, p. 130) informe que a literatura sustenta que "as autoras feministas socialistas, radicais e pós-modernas têm todas sido hostis ao futuro de qualquer forma de feminismo liberal”, não há menção a quais concepções de justiça elas sustentam ou mesmo um registro de quem são as autoras. A visão alternativa rapidamente apresentada, por outro lado, é a da "ética do cuidado" em uma de suas expressões, o pensamento maternal. Nancy Chodorow, Carol Gilligan, Sara Ruddick e Jean Bethke Elshtain, em suas obras escritas entre o final dos anos 1970 e os anos 1980, desenvolveram argumentos - que não são unívocos - sobre a relação entre a posição social das mulheres na esfera doméstica e uma visão de mundo (uma voz e uma ética) diferenciada, que não se referenciaria por direitos abstratos, mas por relações concretas de cuidado ${ }^{6}$.

O feminismo apareceria ainda uma vez no livro, no capítulo sobre pluralismo ("Segmented foundations and pluralism"), mais especificamente em um item intitulado "pluralismo da diferença" (Vincent, 2004). Juntamente com o multiculturalismo e o pós-colonialismo, é situado como teoria crítica a uma narrativa hegemônica incapaz de dar

\footnotetext{
${ }^{5}$ Em um breve comentário sobre diferenças internas ao pensamento liberal, na mesma seção, Vincent (2014) menciona também Mary Wollstonecraft (2016 [1792]), que expressaria um liberalismo baseado nos direitos naturais e, como tal, distinto do liberalismo de base utilitarista de John Stuart Mill. Não há, no entanto, referência à posição feminista de John Stuart Mill e Harriett Taylor Mill (1970), que teria permitido que ampliasse essa discussão.

${ }^{6}$ Para uma breve apresentação desse pensamento, ver Biroli, 2014. Vale observar que essa discussão avançou posteriormente para compreensões que tornam mais complexa a relação entre o papel de mãe e o cuidado, apresentada em uma perspectiva sociopolítica e não essencialista (Biroli, 2015; Hirata; Guimarães, 2012; Molinier, 2014; Tronto, 2013).
} 
conta das vozes dos subalternos e de suas experiências ${ }^{7}$. Mais uma vez, as feministas socialistas e marxistas recebem um comentário vago, sem direito a nomes ${ }^{8}$.

Em outro mapeamento do campo da Teoria Política, dessa vez com a preocupação explícita de compreender como nele se situam os estudos de gênero, Judith Squires (2008 [1999]) organiza as teorias feministas em três eixos, o da "inclusão", o da "reversão" e o do "deslocamento" algo que Vincent (2014) ecoa em sua divisão entre teóricas liberais, teóricas da diferença e teóricas pós-modernas ou da diversidade. Squires faz o duplo esforço de situar essas categorias na produção teórica feminista e na teoria política de modo mais amplo. A “inclusão”, que nas teorias feministas está situada numa abordagem liberal, corresponderia ao que ela vê como enquadramento metateórico "objetivista" na teoria política, mais amplamente. Para Squires (2008 [1999]), o "objetivismo" reúne tanto teorias "normativas" 182 quanto "empíricas", uma vez que haveria dois modos de reivindicar a objetividade, um que a vincula a valores universais (em oposição a valores parciais ou contextuais) e outro que a vincula à racionalidade (em oposição às experiências e às emoções). As teorias feministas também incorporariam o enquadramento "objetivista", mas para reivindicar uma

\footnotetext{
7 Susan Okin e as teóricas da "ética do cuidado" voltam a figurar, mas o rol de autoras se amplia. São citadas as estadunidenses Martha Nussbaum (numa posição feminista liberal), Kate Millett (na crítica ao patriarcado como produtor das diferenças), Andrea Dworkin (na análise do estupro e da pornografia como expressões da visão de mundo masculina), e, em conjunto, as feministas francesas Julia Kristeva, Hélène Cixous e Luce Irigaray (representando a teoria "pós-moderna" francófona), além de breves menções às teóricas estadunidenses Bonnie Honig e Iris Marion Young. O trabalho de Young é apresentado como uma mistura de "feminismo radical, teoria crítica e teoria pós-estruturalista" e a autora é situada como uma das representantes das teorias normativas das diferenças (Vincent, 2004, p. 226).

${ }^{8}$ Vale indagar se e qual feminismo apareceria caso um mapa semelhante da teoria política fosse feito hoje a partir do debate travado no Brasil. Teria peso equivalente às cerca de oito - de 354 páginas - dedicadas a essa corrente no livro de Vincent? Para um mapa sem dúvida incompleto dos diálogos de teóricas brasileiras com o campo das teorias políticas feministas, cf. Biroli e Miguel (2012).
} 
ciência sem viés, isto é, que não seja fundada em estereótipos e no apagamento da posição das mulheres. Em outras palavras, o empírico seria mobilizado como antídoto para um viés social problemático, isto é, para um viés sexista.

A categoria da "reversão", por sua vez, concentraria estudos que discutem o caráter masculino do conhecimento e da prática política, estando associada à moldura metateórica “interpretativa”. O ponto mais relevante aqui é que interpretações feministas contextualizadas valorizariam a relação entre conhecimento e experiência - porque a teoria política vem sendo realizada por homens, ela refletiria suas experiências, daí a necessidade de situar o conhecimento relativamente a outras experiências. Ao mesmo tempo, a experiência situada das mulheres - tão situada quanto a dos homens, é importante ressaltar - levaria a objetos e problemas aos quais a teoria política tem dedicado pouca atenção, como as relações de poder na esfera privada.

A terceira e última categoria a que recorre Judith Squires (2008) é a do "deslocamento", que corresponderia a um enquadramento "genealógico". Nesse caso, o eixo principal é o deslocamento da visão binária do feminino e do masculino, correspondendo a uma abordagem desconstrucionista e discursiva. A produção de conhecimento é vista, nesse caso, como parte da dinâmica de produção do gênero e das identidades, isto é, dos sentidos que assumem em um dado contexto.

No quadro mais abrangente da teoria política estadunidense, no entanto, trata-se do diagnóstico de um silêncio: embora já houvesse, em 1999, quando o livro de Squires foi publicado pela primeira vez, décadas de estudos de gênero na Ciência Política, sua perspectiva e seus resultados não haviam sido incorporados de fato. Isso ocorre (e uso o presente verbal porque não se trata de um problema superado), como ela bem formula, não porque o gênero esteja ausente dos estudos, mas porque está simplesmente presumido em 
concepções masculinas da política apresentadas como se fossem imparciais e neutras (Squires, 2008 [1999], p. 5). Essa é, parece-me, a principal razão pela qual as teorias feministas têm colocado em xeque a diferenciação entre o normativo e o empírico, demonstrando que a realidade que emerge nos estudos empíricos e as referências e pressupostos que informam amplamente as abordagens teóricas são masculinas e androcêntricas. É justamente esse o ponto que será explorado nas próximas seções.

\section{A teoria política sempre foi teoria de gênero}

Uma das posições assumidas mais frequentemente pelas teóricas feministas nas últimas décadas foi o questionamento das bases ontológicas do pensamento político e filosófico. A revisão de cânones do pensamento político moderno esteve presente em obras que podem ser hoje consideradas como desbravadoras na empreitada de situar o feminismo na teoria política contemporânea. É o caso dos estudos já citados de Susan Moller Okin (1989, 1992), Jean Bethke Elshtain (1981) e Carole Pateman (1988). Outras obras se somariam a essas, voltando-se para o pensamento canônico ou para abordagens influentes na modernidade tardia e no liberalismo contemporâneo, para demonstrar que a teoria política é teoria de gênero, e o é justamente em sua recusa a tematizá-1o ${ }^{9}$. Em outras palavras, não tematizando as relações de gênero a teoria política assume uma conformação de gênero da política e do pensamento, colaborando para

\footnotetext{
9 Entre essas obras, e sem qualquer intenção de compor um quadro que fosse minimamente capaz de esgotar o conjunto do pensamento feminista que se volta para a revisão do pensamento de referência para a teoria política, cito Hannah Pitkin (1984), Linda Zerilli (2005) e Nancy Hirschmann (2008). Teóricas socialistas, antirracistas e pós e decoloniais têm, por sua vez, realizado uma dupla revisão crítica, voltada ao mesmo tempo para o pensamento liberal de referência e suas concepções masculinistas da política e para os limites da crítica feminista acadêmica liberal. É esse o caso de autoras como Angela Davis (1981), Bell Hooks (1984), Chandra Mohanty (2003); Ochy Curiel (2007), Patricia Hill Collins (2009 [2000]) e Wendy Brown (1995), entre outras.
} 
reproduzir formas de dominação que excluem e marginalizam as mulheres.

É a isso que Carole Pateman (1989, p. 13) se referia quando definiu a teoria política e a Ciência Política como mais resistentes do que outras disciplinas à reflexão de gênero. Segundo Pateman, a razão para essa resistência estaria em uma compreensão ortodoxa da política, na qual o poder dos homens sobre as mulheres não é percebido como um problema que mereça análise. A dominação de gênero ou patriarcado, isto é, um sistema de dominação de gênero que hierarquiza o masculino e o feminino em desvantagem para as mulheres, organiza largamente as compreensões da política nas tradições de pensamento que a disciplina herda, mas também atualiza. Dessa perspectiva, um olhar reflexivo para o subcampo da teoria política precisa questionar se e de que modo o patriarcado está sendo atualizado nas teorias que produzimos.

Parece-me que uma das formas correntes de atualização do patriarcado na teoria política é a consideração do gênero como problema específico, que remeteria às mulheres e não à política em seus fundamentos. Assim, pode-se até reconhecer os estudos de gênero ou incorporar o gênero como uma variável, sem que necessariamente as relações de gênero sejam compreendidas como algo que compõe as "dinâmicas básicas de poder" (Squires, 2008, p. 18). Isso pode ser ilustrado por um relato de Susan Okin, que, juntamente com Carole Pateman, tem sido uma das teóricas feministas mais reconhecidas na teoria política contemporânea. Em posfácio escrito em 1992 para uma nova edição de Women in Western political thought (1979), a autora relata que nos anos 1980 submeteu a um periódico acadêmico importante de língua inglesa, no campo da filosofia moral, um artigo em que criticava duas abordagens teóricas contemporâneos da 
justiça ${ }^{10}$. O parecer que recebeu, rejeitando o artigo, dizia que de fato o argumento da autora mostrava que a teoria "X" não permitia a inclusão das mulheres, mas ela não teria mostrado que isso tinha um efeito "na própria teoria"11. Reproduzo o comentário de Okin, que vai direto ao ponto que eu levantava:

É difícil imaginar que isso pudesse ser dito de uma teoria política que não incluísse os homens. Deveria ser óbvio embora aparentemente não seja - que apontar para o fato de que uma teoria, em sua forma presente, é incapaz de incluir mais da metade da humanidade significa dizer algo importante sobre "a própria teoria" (Okin, 1992 [1979], p. 313).

A recusa da ampla maioria das abordagens a analisar a dominação masculina como elemento básico das dinâmicas 186 de poder e de organização das instituições tem sido colocada em xeque abertamente por intelectuais mulheres e, destacadamente, por aquelas cujas posições estão relacionadas à crítica e atuação feminista. Os estudos teóricos que produzem tornam explícitas as conexões entre a suspensão da dominação masculina como problema político, as barreiras para que as mulheres se situem como produtoras de conhecimento e a exclusão histórica das mulheres da condição de sujeitos políticos. Por outro lado, perspectivas de gênero (masculinistas nos seus pressupostos) que não tematizam as relações de gênero constituem largamente os programas das disciplinas nos níveis de graduação e pós-graduação, sem que as críticas feministas sejam incluídas. Afinal, tratariam de problemas gerais e universais. Resta, assim, a muitas estudantes a tensão entre tematizar o problema - o que nem

\footnotetext{
${ }_{10}$ Pelo período indicado, podemos supor que fosse uma versão preliminar de um dos textos depois incorporados a Justice, gender, and the family, de 1989.

${ }^{11}$ No original, "on the theory itself".
} 
sempre é bem recebido pelos docentes - e formar-se de modo a dominar o que confere legitimidade ao conhecimento no campo.

Em texto no qual faz um balanço da presença dos estudos feministas na Ciência Política estadunidense, publicado pela primeira vez em 1995, Virginia Sapiro afirma que a baixa incorporação de décadas de estudos teóricos e empíricos com conclusões relevantes para as bases da disciplina pode ser analisada de uma perspectiva sociológica ou de uma perspectiva epistemológica (Sapiro, 1998, p. 69). Na primeira, o problema é a posição estrutural das mulheres na profissão, que levaria à "supressão da atenção às mulheres como sujeitos e a uma concepção acadêmica androcêntrica relativamente incontestada das mulheres, do gênero e da sexualidade" (Sapiro, 1998, p. 69). A segunda, por sua vez, remeteria à dimensão conceitual e aos pressupostos ativados no conhecimento produzido sobre a política. Neste artigo privilegio a dimensão epistemológica, porém explicando-a em conexão com o problema sociológico já apontado. Concordo com a percepção de Sapiro de que é a soma entre a marginalidade das mulheres (na política e na Ciência Política) e valores e práticas correntes nesse campo, como a adesão ao positivismo (ou "objetivismo"), que produzem obstáculos à maior incorporação dos estudos de gênero comparativamente às demais disciplinas das Ciências Sociais ${ }^{12}$.

\footnotetext{
12 Em 2016, embora as mulheres fossem $45 \%$ das pessoas que constavam como associadas efetivas da Associação Brasileira de Ciência Política (ABCP), o Encontro da Associação, o $10^{\circ}$ de sua história, teve $27,8 \%$ de suas mesas-redondas formadas apenas por homens e $61,1 \%$ de mesas nas quais os homens foram maioria. Trata-se de um quadro pouco equilibrado de acesso de mulheres e homens a espaços de prestígio no principal evento da área no Brasil (Marques, 2016). No mesmo encontro, na Área Temática "Teoria Política", menos de 1/3 do conjunto de autores que constam nos anais foi de mulheres (cerca de 27\%). Apenas a título de comparação, em áreas temáticas voltadas predominantemente para a pesquisa empírica, como "Eleições e Representação Política" e "Estado e Políticas Públicas", a presença de mulheres foi bem mais alta - esteve acima de $1 / 3$ na primeira $(38,7 \%)$ e foi majoritária na segunda (63\%), de acordo com os dados disponíveis nos Anais Eletrônicos
} 
As pesquisas feministas têm permitido estabelecer conexões entre quem fala e o mundo de que se fala, entre a produção teórica e as concepções da política que nelas emergem. Sustento que esse é um eixo central na conformação dos questionamentos teóricos feministas - a atenção ao ponto de vista, à perspectiva, à posição social relativa e à dimensão de gênero da produção material tanto quanto da do conhecimento. $\mathrm{O}$ entendimento de que "as ideias não podem ser separadas dos indivíduos que as criam e compartilham" (Collins, 2009 [2000], p. 281) evoca as experiências das mulheres para colocar em xeque dinâmicas excludentes de produção do conhecimento, assim como as realidades parciais que as informam.

O mundo empírico de que têm falado historicamente os teóricos foi vislumbrado, por eles, da perspectiva de quem não experimentou as desvantagens do domínio masculino. Por isso, teria sentido perguntar não apenas quais tradições de pensamento referenciam os debates na teoria política, mas também de que lugar social o mundo foi apreendido - e, assim, quais fatos e experiências puderam desafiar o conhecimento de quem interpelou e interpela o passado e o presente ao tematizar a política. As teorias políticas de gênero (as que os tematizam e as que o pressupõem por não tematizar a dominação masculina) guardam, assim, alguma relação com as políticas de presença no ambiente acadêmico ${ }^{13}$.

do Encontro (<https://cienciapolitica.org.br/eventos/10o-encontro-abcp/anais $>$, acesso em: 3 abr. 2017). Vale conferir também o relatório da American Political Science Association (2005) e as análises de Tolleson-Rinehart e Carroll (2006) sobre a posição das mulheres na Ciência Política estadunidense. A sub-representação das mulheres nos espaços acadêmicos tem levado a movimentos como Women Also Know Stuff (<http://womenalsoknowstuff.com/>, acesso em: 1a ago. 2017) e sua versão brasileira, Mulheres Também Sabem, lançada após a redação da primeira versão deste texto (<https://www.mulherestambemsabem.com/>, acesso em: 1ํago. 2017).

13 Nesse comentário, evoco Phillips (2003 [1995]), em análise da representação de grupos na política orientada a partir do problema da sub-representação das mulheres. O ponto principal é que o caráter não aleatório da sub-representação 
A perspectiva feminista recoloca, assim, as conexões entre o "normativo" e o "empírico". Um dos problemas que assim se apresentam diz respeito a como se estabelecem recortes da realidade, transformados em "dados" ou em referências para análises teóricas que, sustento a partir da crítica feminista, são sempre em algum grau situadas e informadas empiricamente. A alegada abstração das abordagens teóricas normativas apresenta, também, caráter seletivo, na medida em que ativa pressupostos sobre "o indivíduo" e as relações sociais. Em sociedades organizadas por relações de gênero que implicam desigualdades e desvantagens, as experiências vividas pelas mulheres carregam problemas diferentes daqueles que atravessam as experiências dos homens. A abstração do caráter concreto dessas experiências, e das relações de poder em que tomam forma, torna-se ainda mais problemática quando se compreende que as relações de gênero são vivenciadas em seu entrecruzamento com as desigualdades de classe, o racismo e o sexismo. A crítica feminista vem demonstrando que a suspensão dessas desigualdades como problema e o silenciamento das mulheres na produção teórica (e na produção acadêmica de modo mais amplo) colaboram para a reposição de instituições e práticas políticas excludentes. A análise da dominação masculina como artefato social e político demandou um olhar acurado para dimensões até então pouco discutidas nas teorias políticas, assim como recursos conceituais e metodológicos que permitissem conceder a elas centralidade em um campo em que foram historicamente legadas à marginalidade.

Um dos subprodutos dessa crítica é uma certa desconfiança das teorias por parte das intelectuais feministas (Squires, 2008; Collins, 2009 [2000]), algo que ainda

de grupos exige explicações e revela a seletividade de sociedades e instituições definidas como democráticas e/ou liberais. 
caracteriza parte da produção, mas não impediu o surgimento de um conjunto amplo e sistemático de teorias feministas da política. Por outro lado, a reação na área de Ciência Política foi, muitas vezes, a de defender a suposta neutralidade presente nos estudos que não tratam explicitamente das relações de gênero, mobilizando como resistência às teorias feministas a noção positivista de "objetividade" ou, o que tem maior impacto na subárea da teoria política, caracterizando-as como paroquialistas e rejeitando-as em nome de noções como as de "universalidade" e "bem-comum” (Sapiro, 1998, p. 71). Como disse já na apresentação deste artigo, a posição concreta das mulheres, longe de ser o específico que se contrapõe ao universal, é a base a partir da qual as relações de gênero são trazidas à discussão, e política, democracia e justiça são redefinidas em seus sentidos e fronteiras.

Permanece, assim, a crítica de que a teoria política 190 (tanto quanto a Ciência Política) se engaja ativamente na exclusão das mulheres - numa normatividade masculinista, androcêntrica e racista - ao apresentar-se como neutra. Isso ocorre por que a "neutralidade" é, de fato, a desconsideração da dominação de gênero como problema político. A crítica feminista à objetividade tem como especificidade em relação a outras correntes de pensamento, como o marxismo, o fato de que seu ponto de partida é o diagnóstico da exclusão das mulheres e da produção sexista e heteronormativa do gênero em teorias supostamente "neutras". Outra especificidade é o destaque conferido às conexões entre a vida doméstica e pública, colocando como problema central a definição das fronteiras entre a política e o cotidiano da vida familiar e afetiva.

Com base em contribuições teóricas feministas, entendo que seja possível ultrapassar a dicotomia entre o "empírico" e o "normativo" e, assim, potencializar reflexões sobre como diferentes teorias reivindicam o real-empírico ou, em sentido 
oposto, suspendem sua validade - no caso, a de dimensões do empírico em que emergem experiências e vozes diferentes daquelas que têm povoado a ciência "neutra".

A incorporação das experiências e vozes das mulheres tem levado, nas teorias feministas, à emergência de novos objetos, novos materiais de pesquisa e novas perspectivas epistemológicas e metodológicas. Na teoria política, especificamente, o maior impacto se deve à consideração da vida doméstica como questão de justiça e problema político. $\mathrm{O}$ entendimento de que a política ocorre no espaço público - e, em especial, no domínio do Estado - tem sido pressuposto na maior parte das abordagens na teoria política, com exceção do marxismo. Mas mesmo neste, a tematização das relações entre Estado (espaço público político por excelência nas tradições que conformam a disciplina) e capitalismo adentra uma das dimensões do mundo privado, a da propriedade e das relações de trabalho remuneradas, mas raramente a vida doméstica e familiar - a exceção viria de teóricas feministas marxistas ou socialistas como Alexandra Kollontaĭ, Christine Delphy, Heleieth Saffioti, entre outras. É no âmbito doméstico e familiar que dinâmicas significativas de opressão têm incidido sobre a vida das mulheres, limitando suas possibilidades em outras esferas da vida, como a da política institucional (definido como público relativamente ao doméstico e ao mercado) e a do trabalho remunerado (no capitalismo, definido como privado relativamente ao Estado e como público relativamente ao universo doméstico), algo que desenvolvo em Biroli (2016). Por outro lado, a regulação das relações de gênero tem conexão direta com o exercício do poder estatal, configurado em um mundo político predominantemente masculino. Penso não apenas nos casos em que os corpos das mulheres são regulados de modo que reduz sua autonomia pelo controle da sexualidade e da reprodução, mas na recusa histórica de regular e limitar o exercício do poder masculino/paterno 
sobre as mulheres, algo que se reverte a partir das lutas feministas, em contextos de redefinição dos padrões e espaços em que a dominação masculina se organiza (Walby, 1990).

A crítica às fronteiras da política emerge, assim, da tematização da exclusão das mulheres, mas também da atribuição de relevância a suas experiências e da análise de como as identidades têm sido engendradas em regimes de poder específicos. Ao jogar luz sobre dimensões do mundo empírico significativas nas experiências das mulheres, as teorias feministas reconfiguram, ao mesmo tempo, as fronteiras da política e a compreensão das identidades dos agentes políticos. É disso que passo a falar agora.

\section{Fronteiras da política, experiências e identidades}

Embora sejam bastante diversificadas e heterogêneas, as teorias feministas contestam, amplamente, a aderência entre o teórico-conceitual e o universal-abstrato. Mesmo 192 entre teóricas feministas liberais como Susan Okin (1992 [1979]) e Martha Nussbaum (1999), a contestação da neutralidade do pensamento político de referência passou pela demonstração de seu caráter contextual e perspectivo. Com isso, mostraram que o gênero recorta modelos e conceitos teóricos e que os corpos e a posição social dos homens brancos constituem o universal-abstrato em vez de serem neutralizados por ele. Por isso, é possível afirmar que as teorias feministas mobilizam o empírico a contrapelo. Dimensões do empírico associadas às dinâmicas de subalternização são mobilizadas como recurso contestatório e crítico, algo que se estabelece de modos distintos nas teorias feministas mais próximas do liberalismo e naquelas mais distantes, como as marxistas e pós ou decoloniais.

Uma das premissas que atravessam o debate feminista, em sua diversidade, é que o que se passa nos espaços definidos como privados e domésticos é politicamente significativo. $\mathrm{O}$ sentido e as experiências do privado nas vidas 
das mulheres variam, a crítica se estabelece diferentemente quando leva em conta a vida de mulheres brancas de classe média no Norte global ou a de mulheres em áreas rurais da América Latina ou da África. Mas é característico do pensamento feminista que as experiências das mulheres no cotidiano da vida doméstica e familiar importem como problema político.

A configuração da vida familiar é especialmente relevante para o entendimento dos limites à cidadania e à autonomia das mulheres. A ambivalência do valor da privacidade se estabelece porque práticas cotidianas de submissão e violência incidem de forma específica sobre mais da metade da população. O controle diferenciado do Estado sobre os corpos, a divisão sexual do trabalho, a exploração implicada no trabalho não remunerado das mulheres, são alguns dos problemas que podem ficar de fora das análises quando a família é desconsiderada em sua dinâmica interna de poder. Como essa dinâmica não se esgota na esfera doméstica familiar, sua desconsideração é ainda mais significativa. As posições relativas de mulheres e homens na esfera doméstica se desdobram em desvantagens na esfera pública política e nas relações de trabalho remunerado. Uma teoria da democracia que desconsidere as relações de poder na família e a divisão sexual do trabalho deixa de lado um conjunto importante de problemas que interferem no modo como metade da população acessa recursos fundamentais para a participação, como o tempo (Biroli, 2016).

Teóricas feministas têm mostrado que por deixar de lado as conexões entre as esferas pública e privada doméstica, o debate teórico hegemônico aborda de maneira restrita também a configuração da esfera pública. As exclusões que estão implicadas na conformação de uma esfera pública mostram que os valores que nela imperam não são abstratos e universais, mas se definiram, historicamente, segundo a perspectiva de alguns indivíduos e em sua vantagem (Young, 
1990). A projeção de uma esfera pública homogênea, silenciando sobre a existência de públicos distintos e conflitivos, é um de seus efeitos; a restrição do universo da contestação pública legítima, por meio da definição do que é do âmbito privado, isto é, do que não seria de relevância pública e política, é outro (Fraser, 1992; Kritsch, 2012).

Assim, o que é definido como público e o que é definido como privado e/ou doméstico é uma questão política central, ainda que nem sempre considerada. Com base em concepções duais que contrapõem o público, como esfera da justiça e da cidadania, ao privado, como esfera dos afetos e particularidades, as mulheres têm sido excluídas e marginalizadas (Pateman, 1989). É também a dualidade entre o público e o privado que bloqueia o entendimento de que as relações de gênero perpassam todas as esferas da vida, constituindo possibilidades e produzindo identidades.

Mesmo quando a constituição histórica dessa dualidade 194 é percebida como fator fundamental na redefinição das relações de poder e das instituições, a compreensão dos seus efeitos é significativamente limitada pela desconsideração da perspectiva de gênero. Observemos brevemente a tematização da família em Mudança estrutural da esfera pública, de Jürgen Habermas. Nesta, que é uma das narrativas sobre o advento das instituições e valores do mundo burguês no século XVIII que adquiriu maior peso nas Ciências Sociais, a "intimidade duradoura da nova vida familiar" foi vista como um elemento estruturante (Habermas, 2014 [1962], p. 165). Essa intimidade figuraria como um contraponto à intimidade encenada do mundo da nobreza, isto é, às formas "pré-burguesas" da vida familiar que persistiam, em especial no campo. Essas foram assim definidas justamente porque "não se sujeitavam à diferenciação entre 'público' e 'privado'” (Habermas, 2014 [1962], p. 165). O processo de individuação em curso incluía a gradual privatização da vida - dos bens, das formas de circulação das mercadorias e da família. 
As casas se transformavam, figurando como fronteira entre esfera pública e privada e sendo cada vez mais preparadas para o indivíduo, isto é, para uma nova concepção da individualidade e das relações. Nas palavras de Habermas, as pessoas privadas não nasceriam da sociedade, mas surgiriam "de uma vida privada que adquiriu uma forma institucional no espaço interior da família conjugal” (Habermas, 2014 [1962], p. 167).

Embora percebesse a relevância dessa reorganização do domínio da vida doméstica familiar, a análise de Habermas silenciava sobre o caráter patriarcal da sociedade que assim se definia. Por isso foi possível, por exemplo, afirmar que estava em curso "uma emancipação psicológica que corresponde à emancipação no âmbito da economia política" (Habermas, 2014 [1962], p. 167). O próprio autor percebeu os limites dessa análise, comentando-os no prefácio à edição de 1990 de Mudança estrutural da esfera pública, no qual registrou o impacto das teorias feministas na sua apreciação:

Não existe nenhuma dúvida sobre o caráter patriarcal da família conjugal que formava tanto o núcleo da esfera privada da sociedade burguesa como a fonte originária das novas experiências psicológicas de uma subjetividade voltada para si mesma. Contudo, nesse meio-tempo, a crescente literatura feminista aguçou nossa percepção para o caráter patriarcal da própria esfera pública - uma esfera pública que logo se estendeu para além do público leitor, também constituído de mulheres, e assumiu funções políticas. É de se perguntar se as mulheres foram excluídas da esfera pública burguesa da mesma maneira que os trabalhadores, camponeses e a "plebe", isto é, os homens "dependentes" (Habermas, 2014 [1962], p. 45).

Entendo que uma resposta à indagação feita no final do trecho depende da consideração das especificidades da 
dominação patriarcal, como têm ressaltado autoras como Christine Delphy (1998) e Sylvia Walby (1990). A dinâmica que Habermas percebeu como fundamental nas transformações na esfera pública naquele período, que corresponde à formação de uma classe burguesa como "classe universal", isto é, como capaz de definir seus valores e formas de vida como signos de diferenciação e normas de interação, implicou uma reconfiguração das relações de gênero. A separação estrita das esferas pública e privada funcionou, juntamente com normas que firmavam a domesticidade feminina, para distinguir a burguesia de outros estratos sociais, como destaca Nancy Fraser (1992, pp. 114-115), amparada pelos estudos de Geoff Eley (1992).

Uma das críticas mais importantes de Fraser a Habermas, desta vez informada pelos estudos de Mary P. Ryan (1990; 1992), dirige-se à redução da esfera pública moderna à esfera pública burguesa. Nesse ponto, Habermas parece ter aderido à reivindicação da burguesia emergente, isto é, ao próprio mecanismo de universalização que permitia que se impusesse como "classe universal". Havia, no entanto, outras esferas e públicos, "elaborando estilos alternativos de comportamento político e normas alternativas para o discurso público" (Fraser, 1992, p. 116). A análise de Habermas teria suspendido o conflito entre outros públicos e o público burguês, deixando de lado valores e formas de interação alternativas. A incorporação da posição relativa das mulheres na sociedade poderia ter permitido um olhar mais aguçado para esse conflito. Mas novos limites teriam se estabelecido se a incorporação dessa posição não tivesse levado em conta as convergências entre gênero e classe nesse mesmo processo. Em outras palavras, as hierarquias de gênero foram suspensas da análise da esfera pública, tanto quanto as hierarquias que se organizam na convergência entre gênero e classe. 
A dualidade entre as esferas pública e privada é ativada em teorias e instituições que, assim, colaboram para reproduzir e naturalizar hierarquias de gênero. Os padrões encontrados na modernidade europeia são, é claro, localizados no tempo e no espaço. Mas deles advieram normas que foram atualizadas em diferentes contextos, situando as mulheres ou julgando-as a partir do seu papel no universo doméstico familiar. A recusa a conferir relevância política para o mundo doméstico e para a incorporação das mulheres em posição desvantajosa e subalterna na vida pública (Walby, 1990) pode ser lida como estruturalmente ligada à posição dos homens como atores políticos e produtores de conhecimento. Liberados do trabalho cotidiano doméstico e de ser julgados pelo que ali se realiza (ou não se realiza), tendo seu acesso ao mundo público limitado por outras razões que não o fato de serem homens (o que, ao contrário, facilita sua circulação na esfera pública), podem de fato não perceber ou subestimar o gênero como estruturante das diferentes esferas da vida.

Como alertou Carole Pateman (1988) em sua análise das teorias do contrato, a modernidade liberal pode ser definida como antipaternalista, mas não como antipatriarcal. Não é esse, no entanto, o ângulo predominante nas análises $^{14}$. O paternalismo corresponderia a uma forma de organização das relações superada pelo contrato, aquela em que o Estado e os governantes são "como pais" (Pateman, 1988, p. 33). Sua superação, no entanto, não implicou o enfrentamento com o patriarcado, mas a acomodação entre concepções dos direitos individuais referenciadas pelo livre-consentimento e a ampla tolerância social (até certo ponto legal) à subordinação das mulheres. Em outras palavras, as críticas ao paternalismo não implicaram críticas às relações de poder que se organizaram e ainda se organizam, mesmo

\footnotetext{
${ }^{14}$ A esse respeito, ver Dworkin (1988) e Miguel (2015).
} 
que, segundo padrões renovados, sob a égide do "pai" na vida privada. Essas não aparecem na maior parte da literatura como problema político.

Textos precursores do feminismo trataram da organização da família no Ocidente moderno e da normalização das relações conjugais, sexuais e afetivas para confrontar as restrições ao desenvolvimento das mulheres, mas eles não foram incorporados ao debate teórico e aos programas de disciplinas que não tematizam as relações de gênero. No final do século XVIII, a defesa do direito das mulheres à educação e ao desempenho de funções na vida pública carregava ainda o apelo a seu aprimoramento como companheiras dos seus esposos e como mães. Naquele momento, Mary Wollstonecraft via na preparação das meninas para casar-se e agradar aos homens uma raiz das deficiências e injustiças que marcariam suas vidas como mulheres adultas. A socialização as preparava para buscar a atenção masculina 198 e aceitar seu papel como dependentes do casamento e da orientação e sustento dos homens. Posteriormente, a obediência delas exigida no casamento debilitaria sua mente (Wollstonecraft, 2016 [1792], p. 101), enquanto a "opressão política e civil" que lhes impedia de envolver-se nos assuntos coletivos as levaria a um sentimentalismo romântico que reforçava a ideia de que "a tarefa preponderante da vida feminina é agradar” (Wollstonecraft, 2016 [1792], p. 236).

Um século e meio mais tarde, na obra que pode ser tomada como um ponto inaugural do feminismo contemporâneo, Simone de Beauvoir (2008 [1949]) se dedicaria aos mesmos temas em um contexto em que muito já havia mudado. Quando escreveu $O$ segundo sexo, o acesso das mulheres à educação e ao trabalho remunerado já havia se ampliado bastante no Norte global. Na situação em que se encontravam as mulheres europeias e norte-americanas em meados do século XX, o casamento configurava um “projeto fundamental” (Beauvoir, 2008 [1949], pp. 194-195), 
uma "carreira" que implicava benefícios, mas também pesados sacrifícios. Além do domínio econômico, a maior integração do homem na sociedade daria a ele "a direção do casal no campo intelectual, político e moral", permitindo que se realizasse no trabalho e na ação (Beauvoir, 2008 [1949], p. 277). Para a mulher, por outro lado, a liberdade se apresenta como um aspecto negativo, com um custo desigual material e simbolicamente.

Beauvoir, como Wollstonecraft, fazia uma análise teórica informada pela socialização e pelas experiências das mulheres. Viam o mundo da perspectiva das desvantagens de um modo de produção social do gênero fundado na responsabilização diferenciada e na restrição à autonomia das mulheres (Biroli, 2013b; 2016), embora ainda não pudessem lançar mão da terminologia de gênero que predominaria nas críticas a partir dos anos 1980. Estavam ainda mais próximas de uma perspectiva da "inclusão", no sentido definido por Squires (2008) e mencionado antes neste texto, em que a privação das mulheres era analisada, mas já se estabelecia um trânsito entre o diagnóstico de uma exclusão e a análise da reprodução do binário feminino-masculino de modo desvantajoso para as mulheres. Uma das maneiras de analisar a crítica feminista historicamente é, assim, na sua passagem do problema da exclusão das mulheres ao problema da produção do gênero.

Outro ângulo em que se pode compreender as diferentes abordagens no feminismo é o da passagem do problema da exclusão das mulheres para o problema do privilégio, de modo que incorpora significativamente outras variáveis além do gênero. Nesse caso, a reapropriação do mundo empírico se dá a partir de experiências de mulheres trabalhadoras, negras, latinas e imigrantes de diferentes partes do mundo vivendo nos países ricos do Norte global e da produção de conhecimento por mulheres situadas no Sul global. A categoria "mulheres" é questionada por ocultar 
hierarquias internas a esse grupo (Hooks, 1984), destaca-se a configuração conjunta do patriarcado e do capitalismo e seus efeitos nos países do Norte (Walby, 1990) e nos países do Sul (Curiel, 2007; Falquet, 2011; Matos, 2010), levando-se em conta os fluxos migratórios (Hirata; Le Doaré, 1998).

A ênfase em uma economia política dos privilégios que ultrapassa a dualidade entre o masculino e o feminino permite compreender que a produção social do gênero não se dá de forma absoluta relativamente a outras dinâmicas de opressão. Esse debate vem sendo produzido, no âmbito do feminismo, por teóricas socialistas, antirracistas e pós e decoloniais. Também aqui, não se trata de algo novo, mas sim de reflexões e pesquisas marginalmente incorporadas aos debates na teoria política e na Ciência Política de modo mais amplo. Textos pioneiros do feminismo socialista, como aqueles escritos por Alexandra Kollontaĭ, nas décadas iniciais do século XX, questionavam a represen200 tação idílica das mulheres na família e sua idealização como mães, mostrando que incidiam de maneira muito distinta sobre as mulheres segundo sua posição de classe. Em seu contexto, Kollontaĭ entendia que o processo de libertação das mulheres estava contido na revolução comunista, algo que seria problematizado posteriormente (Arruzza, 2013). Sua atenção à opressão diferenciada que incidia sobre as mulheres anteciparia algo que seria fundamental aos debates na segunda metade do século XX: não existe posição ou vivência que seja comum a todas as mulheres ${ }^{15}$.

A dualidade entre público e privado e a divisão sexual do trabalho, temas que constituem a crítica feminista, foram elaborados de maneira muito diversa segundo o grau

15 Conferir, em especial, "Mulher trabalhadora e mãe", de 1914, no qual compara a gravidez e o parto de quatro mulheres: a mulher do diretor da fábrica, a lavadeira, a arrumadeira e a trabalhadora da fábrica de tecidos. "O comunismo e a família", de 1920, por sua vez, exporia as ambivalências que marcaram o debate sobre mudanças na legislação e nos valores associados ao casamento e à família após a Revolução Russa (Kollontaĭ, 1977). 
de incorporação das convergências entre gênero, classe e raça nas análises. No chamado "pensamento maternalista", que suscitou vários debates entre pesquisadoras estadunidenses (mas não só) a partir do final dos anos 1970, emergem experiências de mulheres brancas de classe média (Ruddick, 1989), de modo bastante distinto do que seria tematizado quando maternidade e família são objetos de teorização de feministas negras no mesmo país, no mesmo período (Collins, 1995), ou na América Latina, em que as experiências da maternidade se entrelaçam às do racismo e à da pobreza e a noção de "matriarcado da miséria" se impõe (Carneiro, 2011, p. 130) ${ }^{16}$.

Patricia Hill Collins diferencia não apenas a experiência da maternidade, mas o próprio caráter da experiência nas vidas das mulheres, uma vez que a privatização da vida familiar entre as brancas implicaria conexão com aqueles a quem estão ligadas por laços conjugais e de sangue, mas também uma forma de separação relativamente a outros grupos e laços possíveis. Enquanto isso, para as mulheres negras, a vivência da maternidade se daria de forma mais marcada pelos laços comunitários e pelo ativismo (Collins, 2009 [2000], p. 209). Vale observar que em todos os casos estamos falando de elaborações que se definem a partir de experiências de mulheres e em esforços teóricos de conceituação no campo do feminismo. Fora dele, prevalece o silêncio sobre a maternidade como problema político (Biroli, 2015).

Trata-se, assim, de levar em consideração as conexões entre sujeitos, experiências e produção de conhecimento. Dimensões das experiências são excluídas de uma produção de conhecimento amplamente masculina e que não tematiza as relações de gênero, algo que pode se repetir quando mulheres melhor posicionadas nas relações de privilégio

16 Discuti as abordagens maternalistas mais amplamente em Biroli (2013b, 2014). Para críticas ao pensamento maternal, cf. Dietz (1985), Friedman (1995) e Miguel (2001). 
em termos de classe e de gênero se propõem a falar pelas demais, universalizando suas experiências (Hooks, 1984). Os circuitos da subjugação do conhecimento não se esgotam, assim, nas relações de gênero. "Conhecimentos subjugados" emergem de diferentes localizações sociais, em tensão com aqueles "usados pelos poderosos para legitimar reivindicações de conhecimento que justificam seu direito a comandar" (Collins, 2009 [2000], pp. 289-290).

O limite à transposição das experiências como conhecimento legítimo é um problema importante e remete às relações de poder institucionalizadas. A análise da economia política da produção e circulação do conhecimento é, assim, fundamental. Na teoria política feminista, o ponto de vista é tratado como questão política para a democracia ao menos desde os anos 1970, embora tenham inicialmente prevalecido considerações epistemológicas sobre o caráter social do "lugar de fala" (Harding, 1986; Hartsock 1998 [1983]). Ao 202 mesmo tempo, análises de experiências femininas do corpo e do mundo doméstico-familiar se desdobram em considerações sobre agência e opressão: investidas de sentidos que têm sido silenciados e estigmatizados, reduzindo o valor das vidas das mulheres de acordo com sua localização no mundo (Segato, 2016) e, numa perspectiva em que a diferenciação entre o feminino e o masculino se estabelece, restringindo a partir de seus corpos a autonomia possível e localizando-as em espaços e práticas repletos de significados (Young, 2005). Mais uma vez, a desvantagem se realiza como apagamento, mas não faz desaparecerem experiências e lutas (Falquet, 2011), que são, entretanto, subincorporadas nas análises dos conflitos e padrões de contestação na contemporaneidade. A crítica aos ideais da universalidade e da imparcialidade corresponde à valorização do conhecimento parcial, incorporando normativamente o entendimento de que posições sociais estruturais, relativas, produzem experiências particularmente localizadas e um conhecimento específico dos 
processos sociais (Young, 2000, p. 136) e dando especial relevância às vozes das mulheres (Pinto, 2010).

\section{Considerações finais}

As reflexões aqui apresentadas versaram sobre o lugar das teorias feministas na Ciência Política e na subárea da teoria política e, em seguida, sobre a conformação das críticas feministas da política. A exclusão histórica e a inclusão desigual das mulheres na esfera pública tornam a crítica feminista peculiar: como sujeitos da teorização, as mulheres se debruçam sobre práticas que as marginalizam e narrativas que as silenciam. Por isso o problema da relevância política das suas experiências e da própria dominação masculina se torna tão central. Argumentei que, ao elaborá-lo, as teóricas feministas têm redefinido as conexões entre o normativo e o empírico, entre as teorias e as dimensões do empírico que as informam.

As teorias da política têm sido informadas por um mundo no qual o gênero organiza as relações na esfera pública e na esfera privada e incide sobre a configuração interna e as fronteiras da política. Por isso entendo, como foi dito, que teorias políticas são teorias de gênero mesmo quando não o tematizam. A questão é se o gênero é tratado como problema político, se é incorporado apenas como variável demográfica ou se é completamente silenciado como dimensão das relações de poder e das experiências.

Com base nessa crítica, um primeiro questionamento que me parece necessário a uma discussão sobre "o que estamos fazendo quando praticamos teoria política" é em que medida a posição relativa das mulheres e suas experiências vividas informam o universo das teorias. É preciso, ainda, questionar o que está sendo pressuposto e explicitado como politicamente relevante por essas teorias. Em outras palavras, é preciso compreender se e em que medida as teorias atualizam a dualidade entre público e privado, silenciando 
sobre as relações de poder na esfera doméstica e sobre o caráter patriarcal da esfera pública.

Nas teorias feministas, as experiências das mulheres é que permitiram redefinir as fronteiras entre público e privado. É a partir delas que a divisão sexual do trabalho, a violência na vida familiar, a incidência diferenciada do controle do Estado sobre os corpos, assim como a acomodação entre noções abstratas de liberdade e condições socialmente toleradas de subordinação das mulheres, entre outras questões, vieram à tona como problemas políticos de primeira ordem.

Outras dimensões do empírico emergem, assim, de esforços normativos pela reconfiguração de posições e identidades na luta política. A revisão do pensamento político e a recolocação dos problemas relativos aos limites da democracia se fizeram no diálogo sistemático entre a produção teórica e o ativismo. O ativismo feminista de mulheres lésbicas, negras, latinas e trabalhadoras, por sua vez, tem esta204 belecido outros deslocamentos e tem sido incorporado em abordagens que colocaram em questão o binarismo feminino-masculino e as abstrações necessárias para se sustentar o sujeito coletivo "mulheres" nas teorias e nas lutas políticas.

As teorias feministas politizam o mundo para além das fronteiras da política institucional e, com isso, intensificam o caráter político da teoria política. Por outro lado, a suspensão da perspectiva de gênero contribui para sua despolitização. Digo isso porque o que está em jogo não é a exclusão ou inclusão das mulheres, mas sim uma dimensão estruturante das relações de poder nas diferentes esferas da vida, constitutiva das instituições e dos valores políticos.

As conexões entre o mundo nas teorias e as teorias no mundo envolvem também uma consideração de com quem estabelecemos diálogo e como as teorias que fazemos incidem sobre o mundo. Em seu mapeamento da teoria política discutido nas seções iniciais desse artigo, Andrew Vincent (2004) chama a atenção para o fato de que a especialização 
cada vez maior implicou um fechamento - teóricos falam entre si e praticam, em larga escala, uma metateoria que pouco faz além de contribuir para sua carreira profissional, por sua vez referenciada por pares também cada vez mais especializados e "institucionalizados", isto é, com competências desenvolvidas para situar-se no mundo das regras e julgamentos acadêmicos. Susan Okin termina o posfácio de 1992, aquele mesmo em que discute em que medida a crítica feminista coloca em questão "a teoria em si", fazendo um chamado de volta à política, dirigido nesse caso às teorias feministas da política. Seu ponto é, basicamente, que teorizamos muito e pouco nos preocupamos com o papel político das teorias. É interessante que isso tenha que ser colocado também para um campo teórico que nasce, como procurei mostrar aqui, da crítica a teorias que naturalizam exclusões e hierarquias de gênero justamente por não considerarem a dominação masculina como um problema.

Uma dobra das teorias políticas incorpora o empírico como matéria para o debate teórico. Nesse caso, o ponto é que diferentes dimensões do empírico se transformam em problemas teóricos, dependendo de quais relações e sujeitos são considerados e praticam teoria política. Simultaneamente, outra dobra pesa sobre os embates políticos concretos. $\mathrm{O}$ ponto é, então, em que medida as teorias confrontam ou naturalizam hierarquias e formas de concentração de poder. A oposição entre "normatividade" e "empiria" pode ser vista como uma recusa dessa segunda dobra e, com ela, da tematização da economia política do conhecimento.

No feminismo, essas dobras têm assumido a forma de uma escuta e da afirmação do caráter ativo das teorias. A escuta implica "a parcialidade, e não a universalidade" (Collins, 2009 [2000], p. 290), enquanto a assunção de seu caráter ativo implica o enfrentamento, e não a recusa, dos conflitos políticos vivenciados em um dado contexto histórico. 


\section{Flávia Biroli}

é professora do Instituto de Ciência Política da UnB, coordenadora do Grupo de Pesquisa sobre Democracia e Desigualdades (Demodê) e pesquisadora do CNPq.

\section{Bibliografia}

AMERICAN POLITICAL SCIENCE ASSOCIATION. 2005. Women's advancement in political science: a report on the APSA workshop on the advancement of women in academic political science in the United States. Washington, DC: American Political Science Association.

ARRUZZA, Cinzia. 2013. Dangerous liaisons: the marriages and divorces of marxism and feminism. London: Merlin.

BEAUVOIR, Simone de. 2008. O Segundo sexo (Volume 2: A experiência vivida). Lisboa: Bertrand.

BIROLI, Flávia. 2010. Gênero e família em uma sociedade justa: adesão e crítica à imparcialidade no debate contemporâneo sobre justiça. Revista de Sociologia e Política, v. 18, n. 36, pp. 51-65. 2013a. Autonomia, opressão e identidades: a ressignificação da experiência na teoria política feminista. Revista Estudos Feministas, v. 21, n. 1, pp. 81-105.

2013b. Autonomia e desigualdades de gênero: contribuições do feminismo para a crítica democrática. Niterói: Eduff.

. 2014. O público e o privado. In: MIGUEL, Luis Felipe;

BIROLI, Flávia. Feminismo e política: uma introdução. São Paulo, Boitempo, pp. 31-46.

2015. Responsabilidades, cuidado e democracia. Revista Brasileira de Ciência Política, n. 18, pp. 81-117.

. 2016. Divisão sexual do trabalho e democracia. Dados, v. 59, n. 3, pp. 719-754.

BIROLI, Flávia; MIGUEL, Luis Felipe (orgs.). 2012. Teoria política e feminismo: abordagens brasileiras. Vinhedo: Horizonte.

BROWN, Wendy. 1995. States of injury: power and freedom in late modernity. Princeton, NJ: Princeton University Press.

BUTLER, Judith P. 1999 [1990]. Gender trouble: feminism and the subversion of identity. New York: Routledge.

CARNEIRO, Sueli. 2011. Racismo, sexismo e desigualdade no Brasil. São Paulo: Selo Negro. 
COLLINS, Patricia H. 1995. Black women and motherhood. In: HELD, Virginia. (ed.). Justice and care: essential readings in feminist ethics.

Boulder: Westview, pp. 117-138. 2009 [2000]. Black feminist thought: knowledge, consciousness, and the politics of empowerment. New York: Routledge.

CURIEL, Ochy. 2007. Crítica poscolonial desde las prácticas políticas del feminismo antirracista. Nómadas, n. 26, pp. 92-101.

DAVIS, Angela Y. 1981. Women, race, Ev class. New York: Vintage.

DIETZ, Mary G. 1985. Citizenship with a feminist face: the problem with maternal thinking. Political Theory, v. 13, n. 1, pp. 19-37.

DELPHY, Christine. 1998. L'ennemi principal. In: . L'Ennemi principal: économie politique du patriarcat. Paris: Sylpese, pp. 31-52.

DWORKIN, Gerald. 1988. The theory and practice of autonomy. Cambridge, MA: Cambridge University Press.

ELEY, Geoff. 1992. Nations, publics, and political cultures: placing Habermas in the nineteenth century. In: CALHOUN, Craig. (ed.). Habermas and the public sphere. Cambridge: MIT Press, pp. 289-339.

ELSHTAIN, Jean B. 1981. Public man, private woman: women in social and political thought. 2. ed. Princeton: Princeton University Press.

FALQUET, Jules. 2011. Por las buenas o por las malas: las mujeres en la globalizatión. Bogotá: Universidad Nacional de Colombia.

FOUCAULT, Michel. 1997 [1969]. A arqueologia do saber. Rio de Janeiro: Forense Universitária.

FRASER, Nancy. 1992. Rethinking the public sphere: a contribution to the critique of actually existing democracy. In: CALHOUN, Craig. (ed.). Habermas and the public sphere. Cambridge: MIT Press, pp. 109-142.

FRIEDAN, Betty. 2001 [1963]. The feminine mystique. New York: W.W. Norton.

FRIEDMAN, Marilyn. 1995. Beyond caring: the de-moralization of gender. In: HELD, Virginia. (ed.). Justice and care: essential readings in feminist ethics. Boulder: Westview, pp. 61-78.

HABERMAS, Jürgen. 2014 [1962]. Mudança estrutural da esfera pública. São Paulo: Unesp.

HARDING, Sandra G. 1986. The science question in feminism. Ithaca: Cornell University Press.

HARTSOCK, Nancy C. M. 1998 [1983]. The feminist standpoint: developing the ground for a specifically feminist historical materialism. In: The feminist standpoint revisited and other essays. Boulder:

Westview, pp. 105-132. 
HIRATA, Helena; LE DOARÉ, Hélène. 1998. Les paradoxes de la mondialisation. Cahier du Geddist, n. 21, pp. 5-34.

HIRATA, Helena; GUIMARÃES, Nadya A. (orgs.). 2012. Cuidado e cuidadoras: as várias faces do trabalho do care. São Paulo: Atlas.

HIRSCHMANN, Nancy J. 2008. Gender, class E freedom in modern political theory. Princeton, NJ: Princeton University Press.

HOOKS, Bell. 1984. Feminist theory: from margin to center. 2. ed. New York: South End Press, 1984.

JAWDAT, Abu-El-Haj. 2014. Robert Dahl (1915-2014): poder politico, liberalização e contestação nas democracias. Revista Brasileira de Ciência Política, n. 13, pp. 7-17.

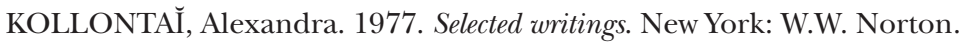
KRITSCH, Raquel. 2012. O gênero do público. In: BIROLI, Flávia; MIGUEL, Luis Felipe. (orgs.). Teoria política e feminismo. Vinhedo: Horizonte, pp. 17-45.

MARQUES, Danusa. 2016. Cadê as mulheres no $10^{\circ}$ Encontro da ABCP? Blog do Demodê, Brasília, DF, 8 set. 2016. Disponível em: <https://goo. gl/a4ijXD>. Acesso em: 29 set. 2017.

MATOS, Marlise. 2010. Movimento e teoria feminista em sua nova onda: entre encontros e confrontos, é possível reconstruir a teoria feminista a partir do sul global? Revista de Sociologia e Política, v. 18, n. 36, pp. 67-92.

MIGUEL, Luis Felipe. 2001. Política de interesses, política de desvelo: representação e "singularidade feminina". Revista Estudos Feministas, v. 9, n. 1, pp. 253-267. 2015. Autonomia, paternalismo e dominação na formação das preferências. Opinião Pública, v. 21, n. 3, pp. 601-625.

MILL, John S.; MILL, Harriet T. 1970. Essays on sex equality. Chicago: University of Chicago Press.

MOHANTI, Chandra T. 2003. Feminism without borders: decolonizing theory, practicing solidarity. Durham: Duke University Press.

MOI, Toril. 1999. What is a woman? and other essays. Oxford: Oxford University Press.

MOLINIER, Pascale. 2014. Le travail du care. Paris: La Dispute.

NUSSBAUM, Martha C. 1999. Sex and social justice. Oxford: Oxford University Press.

OKIN, Susan M. 1989. Justice, gender, and the family. New York: Basic. 1992 [1979]. Women in Western political thought. Princeton, NJ:

Princeton University Press. 
PATEMAN, Carole. 1988. The sexual contract. Stanford: Stanford University Press.

1989. The disorder of women: democracy, feminism and political theory.

Stanford: Stanford University Press.

PHILLIPS, Anne. 2003 [1995]. The politics of presence: the political

representation of gender, ethnicity, and race. Oxford: Oxford

University Press.

PINTO, Céli. R. J. 2010. Feminismo, história e poder. Revista de Sociologia e Política, v. 18, n. 36, pp. 15-23.

PITKIN, Hanna F. 1984. Fortune is a woman: gender and politics in the thought of Niccolo Machiavelli. Chicago: University of Chicago Press.

RUDDICK, Sarah. 1989. Maternal thinking: towards a politics of peace.

Boston: Women's Press.

RYAN, Mary P. 1990. Women in public: between banners and ballots, 1825-1880.

Baltimore: John Hopkins University.

. 1992. Gender and public access: women's politics in nineteenth-

century America. In: CALHOUN, Craig. (ed.). Habermas and the public

sphere. Cambridge: MIT Press, pp. 259-288.

SAFFIOTI, Heleieth I. B. 2013 [1976]. A mulher na sociedade de classes: mito e realidade. São Paulo: Expressão Popular.

1992. Gender and public access: women's politics in nineteenthcentury America. In: CALHOUN, Craig. (ed.). Habermas and the public sphere. Cambridge, MA: MIT Press, pp. 259-288.

SAPIRO, Virginia. 1998. Feminist studies and political science - and vice versa. In: PHILLIPS, Anne. (ed.). Feminism and politics. Oxford:

Oxford University Press, pp. 67-91.

SEGATO, Rita L. 2016. La guerra contra las mujeres. Madrid: Tranficantes de Sueños.

SCOTT, Joan W. 1986. Gender: a useful category of historical analysis. American Historical Review, v. 91, n. 5; pp. 1053-1075.

SQUIRES, Judith. 2008 [1999]. Gender in political theory. Cambridge, UK: Polity.

TOLLESON-RINEHART, Sue; CARROLL, Susan J. 2006. "Far from ideal": the gender politics of political science. The American Political Science Review, v. 100, n. 4; pp. 507-513.

TRONTO, Joan. C. 2013. Caring democracy: markets, equality, and justice. New York: New York University Press.

VINCENT, Andrew. 2004. The nature of political theory. Oxford: Oxford University Press. 
YOUNG, Iris. M. 1990. Justice and the politics of difference. Princeton: Princeton University Press. . 2000. Inclusion and democracy. Oxford: Oxford University Press. 2005. On female body experience. Oxford: Oxfor University Press.

WALBY, Sylvia. 1990. Theorizing patriarchy. Oxford: Basil Blackwell.

WOLLSTONECRAFT, Mary. 2016 [1792]. Reivindicação dos direitos da mulher. São Paulo: Boitempo.

ZERILLI, Linda M. G. 2005. Feminism and the abyss of freedom. Chicago: The University of Chicago Press. 


\section{D)}

\section{TEORIAS FEMINISTAS DA POLÍTICA, EMPIRIA E NORMATIVIDADE}

\section{FLÁVIA BIROLI}

Resumo: $\mathrm{O}$ artigo procura investigar o que fazemos quando produzimos teoria política hoje a partir das teorias feministas da política, situando-as relativamente aos desenvolvimentos da ciência política na segunda metade do século $\mathrm{XX}$. Analisa as conexões entre o empírico e o normativo em teorias que colocam em xeque o descolamento entre o conhecimento produzido, a posição de quem produz conhecimento e os valores predominantes em dado contexto social. A partir de um conjunto heterogêneo de abordagens, afirma que as teorias políticas são teorias de gênero mesmo quando não tratam dessa temática, discutindo as fronteiras entre o que é e o que não é considerado politicamente relevante no debate teórico.

Palavras-chave: Teoria Política Feminista; Gênero; Ciência Política; Empírico; Normativo; Neutralidade Científica.

\section{FEMINIST THEORIES ON POLITICS, EMPIRISM AND NORMATIVITY}

Abstract: The article investigates what we are doing when we practice political theory today, analyzing feminist theories of politics in reference to the development of political sciences in the second half of the twentieth century. It discusses the connections between the empirical and the normative in theories that put into question the detachment between the knowledge produced, the position of who produces knowledge, and predominant values in a given social context. From a heterogeneous set of approaches, the article asserts that political theories are gender theories even when they do not 
address gender, discussing the frontiers between what is and what is not considered politically relevant in theoretical debate.

Keywords: Feminist Political Theory; Gender; Political Science; Empirical; Normative; Scientific Neutrality.

Recebido: 02/05/2017 Aprovado: 12/07/2017 